\title{
Gómez González, Aitor; Díez Palomar, Javier; Ormazábal Unzué, Javier; Flecha García, Ramón; Vilà Baños, Ruth (2012) Estadística Básica para educadores. Madrid: Síntesis.
}

Estadística básica para educadores es un libro que ofrece una herramienta práctica para todas aquellas personas que desean aproximarse al mundo de la educación de una manera crítica y seria. A través de sus páginas, los autores nos ofrecen de manera sencilla y a veces intuitiva los conocimientos imprescindibles de la estadística para desempeñar nuestra tarea como profesionales de la educación.

Cada vez más la sociedad exige a los centros educativos, al profesorado y a las personas que nos dedicamos a la investigación en el ámbito educativo que rindamos cuentas de nuestras actuaciones. La eclosión de estadísticas y estudios tales como PISA no hace sino reforzar esta idea de que las personas que trabajamos en el ámbito de la educación tenemos que asumir la parte de la responsabilidad que nos corresponde sobre los resultados académicos que obtienen nuestros estudiantes. Aplicar actuaciones educativas sin tener información de primera mano, seria y rigurosa, puede ser motivo de tremendos errores que acaban pagando los y las estudiantes con sus calificaciones. La estadística nos ofrece por un lado una herramienta de evaluación de nuestras actuaciones, pero también es un "faro" que nos ilumina para saber qué decisiones tomar.

En este libro los autores no hacen una exposición de la matemática que hay detrás de la estadística. Eso ya lo hacen otros manuales, de sobra conocidos. En este libro, en cambio, se nos ofrecen pautas para entender la herramienta, para saber cómo funciona y para qué sirve, y, quizás lo más importante, para saber interpretar qué nos dice una vez que hemos decidido utilizarla.

La estadística es una ciencia que trabaja con datos. Es, por definición, la ciencia del Estado también, la ciencia que los estadistas han utilizado durante décadas para gestionar, para tomar sus decisiones. Tal y como explican los autores en el libro, esta capacidad de la estadística para informar (y a veces justificar) decisiones ha llevado tanto a grandes aciertos (cuando se usa de manera sabia) como a terribles errores (cuando se manipula de manera interesada). Casos tan paradigmáticos como el Informe Jencks en virtud del cual se eliminó la inversión pública en educación en los EE.UU. durante los años sesenta del siglo pasado, en plena lucha de la comunidad afroamericana por los derechos civiles y la igualdad de oportunidades, son ejemplo del peligro que puede llegar a conllevar el mal uso de la estadística. 
Por eso es tan importante tener una buena formación básica en esta ciencia. Ahora más que nunca estamos desbordados de datos, de información. Este libro nos informa de cómo usar las diferentes herramientas estadísticas (los estadísticos) para poder sistematizar dicha información, y obtener de esa manera imágenes comprensibles de los fenómenos educativos (y sociales) que de otra manera quedan "ocultos" por el exceso de "ruido" que significa tener demasiados datos a la vez.

Por otro lado, la estadística también nos ayuda a hacer predicciones. No solo es cierto para las predicciones del "tiempo." Las personas que presentan la predicción del tiempo se basan en complejos modelos de regresión donde cruzan diversas variables para saber con un cierto nivel de probabilidad si hará sol o bien lloverá. En diversas páginas web de servicios oficiales de meteorología en todo el mundo, es posible consultar libremente esta información e incluso saber con qué grado de probabilidad va a ocurrir la predicción de "hacer sol." También es cierto para las variables educativas. La regresión es una potente herramienta que nos permite predecir por ejemplo la nota media esperada de un grupo clase (o de un individuo), conforme a una serie de registros anteriores, sobre los que esta herramienta se basa para hacer la predicción. Asumiendo una relación entre los datos recogidos previamente, se puede "modelizar" a partir de una recta de regresión, y con la ecuación de dicha recta es posible "predecir" el comportamiento académico más probable de ese estudiante. Esta información desde luego puede ser clave para tomar decisiones sobre el plan de estudios, el enfoque didáctico, o las actividades a realizar para enfocar el nuevo tema del currículum.

La estadística, por tanto, vemos que tiene un valor tremendamente útil para nuestro trabajo, tanto como fuente de información para evaluar, como para describir lo que está ocurriendo y para tomar decisiones en base a datos científicos, no en base a ideas vagas u ocurrencias sin ningún tipo de referente sólido.

Este libro ofrece una introducción amena, directa y sencilla a este mundo complicado que puede llegar a ser la estadística, haciendo un intento de convertirlo en algo pleno de sentido para la persona que lea sus páginas.

Joan Cabré Olivé. Departament de Pedagogia. Universitat Rovira i Virgili 